\title{
Inativação termoquímica de Escherichia coli, Staphylococcus aureus e Salmonella enterica Enteritidis por óleos essenciais
}

\author{
Thermochemical inactivation of Escherichia coli, Staphylococcus aureus and \\ Salmonella enterica Enteritidis by essencial oils
}

\author{
Alcilene de Abreu Pereira ${ }^{\mathrm{I}}$ Roberta Hilsdorf Piccoli ${ }^{\mathrm{I}^{*}}$ Nádia Nara Batista ${ }^{\mathrm{II}}$ \\ Natália Gonçalves Camargos ${ }^{\text {II }}$ Maíra Maciel Mattos de Oliveira ${ }^{\text {II }}$
}

\section{RESUMO}

O controle do crescimento microbiano tanto na indústria de alimentos quanto em ambientes hospitalares é de extrema importância. Entretanto, observa-se aumento da resistência dos microrganismos aos desinfetantes mais empregados, observandose a necessidade de estudos com novos antimicrobianos. Assim, o objetivo desse trabalho foi avaliar a atividade antimicrobiana e a curva de morte termoquímica de soluções desinfetantes de óleos essenciais sobre Escherichia coli, Staphylococcus aureus e Salmonella Enteritidis. Foram utilizados os óleos essenciais de Thymus vulgaris (tomilho), Elettaria cardamomum (cardamomo), Eugenia caryophyllus (cravo botão) e Foeniculum vulgare dulce (funcho doce). As concentrações mínimas inibitórias foram determinadas utilizando-se a técnica de diluição em placas. As concentrações testadas foram de (\%): 0,00; 0,25; 0,5; 1,0; 2,0; 2,5; 3,0; 3,5; 4,0; 4,5; e 5,0. Escherichia coli foi a única bactéria sensível a todos os óleos em concentrações abaixo de 5\%. Cravo da índia não inibiu o crescimento de $\boldsymbol{S}$. aureus nas concentrações testadas. Somente o óleo essencial de tomilho inibiu o crescimento de Salmonella Enteritidis. Observando-se as curvas de morte termoquímica de S. aureus, nota-se que a solução desinfetante contendo óleo essencial de tomilho foi a mais eficiente, tanto a 25 quanto a $40^{\circ} \mathrm{C}$, sendo necessário apenas $10 \mathrm{~min}$. de contato para não serem mais detectadas células viáveis. A solução desinfetante contendo $0,25 \%$ de óleo essencial de tomilho, tanto a 25 quanto a $40^{\circ} \mathrm{C}$, eliminou as células de $\mathrm{S}$. Enteritidis após10min. de contato. Já pra E. coli, os melhores resultados foram obtidos com as soluções desinfetantes contendo óleos essenciais de funcho doce e cravo da india a 25 e $40^{\circ} \mathrm{C}$ e tomilho a $40^{\circ} \mathrm{C}$. Todos os tratamentos, exceto aqueles contendo óleo essencial de cardamomo, reduziram o número de células viáveis das bactérias testadas em pelo menos 5 ciclos log, sendo considerados adequados para utilização como desinfetantes.

Palavras-chave: desinfetante, Thymus vulgaris, Elettaria cardamomum, Eugenia caryophyllus.

\section{ABSTRACT}

The control of microbial growth in the food industry and in hospital environments is extremely important. However there is increasing resistance of microorganisms to disinfectants normally applied, which leads to the need for new antimicrobial studies. The aim of this study was to evaluate the antimicrobial activity and thermochemical death curve of disinfectant solutions from essential oils on Escherichia coli, Staphylococcus aureus and Salmonella Enteritidis. The essential oils of Thymus vulgaris (thyme), Elettaria cardamomum (cardamom), Eugenia caryophyllus (clove bud) and Foeniculum vulgare dulce (sweet fennel) were used. The minimum inhibitory concentrations were determined using dilution technique in Petridish. The concentrations tested were (\%): $0.00,0.25,0.5,1.0,2.0,2.5,3.0,3.5,4.0,4.5$, and 5.0. Escherichia coli were the only bacteria sensitive to all oils at concentrations below 5\%. Cloves did not inhibit the growth of S. aureus at the concentrations tested. Only the thyme essential oil inhibited the growth of Salmonella Enteritidis. Observing the thermochemical death curves of $\mathbf{S}$. aureus one can see that the disinfectant solution containing thyme essential oil was the most effective, both at 25 and $40^{\circ} \mathrm{C}$, requiring only $10 \mathrm{~min}$ contact to no longer detecte viable cells. The disinfectant solution containing $0.25 \%$ thyme essential oil, both at 25 and $40^{\circ} \mathrm{C}$ removed $\boldsymbol{S}$. Enteritidis cells after 10min. contact. For $\boldsymbol{E}$. coli the best results were obtained with disinfectant solutions containing fennel and sweet clove essential oils at 25 and $40^{\circ} \mathrm{C}$ and thyme at $40^{\circ} \mathrm{C}$. All treatments, except that containing cardamom essential oil, reduce the number of viable bacteria cells tested in at least $5 \log$ cycles, being considered suitable for use as disinfectants.

Key words: disinfectant, Thymus vulgaris, Elettaria cardamomum, Eugenia caryophyllus.

'Programa de Pós-graduação em Microbiologia Agrícola, Departamento de Biologia, Universidade Federal de Lavras (UFLA), Lavras, MG, Brasil.

IDepartamento de Ciência dos Alimentos, UFLA, CP 3037, 37200-000, Lavras, MG, Brasil. E-mail: rhpiccoli@dca.ufla.br.*Autor para correspondência.

IIIInstituto Federal de Educação, Ciência e Tecnologia do Espírito Santo, Campus Venda Nova do Imigrante, Venda Nova do Imigrante, ES, Brasil. Recebido 24.01.14 Aprovado 26.04.14 Devolvido pelo autor 25.07.14 


\section{INTRODUÇÃO}

Tanto a indústria de alimentos quanto a área da saúde necessitam de agentes antimicrobianos para garantir a inocuidade alimentar e a saúde do ser humano, respectivamente. Assim, cada vez mais agentes antimicrobianos são utilizados. Simultaneamente a esse fato, a investigação de novos agentes antimicrobianos tem ganhado destaque, devido ao aumento do número de bactérias que se mostram resistentes aos agentes desinfetantes utilizados, tanto na área médica quanto na indústria de alimentos (DAVIDSON \& HARRISON, 2002). Embora existam vários antimicrobianos, com diferentes modos de ação, as bactérias podem desenvolver resistência a eles, devido, principalmente, à exposição das células a concentrações subletais de desinfetantes nas etapas de higienização na indústria ou nas desinfecções em ambientes hospitalares.

Exemplo mais recente é o aparecimento de bactérias multirresistentes produtoras de carbapenemase, que estão causando mortes devido a infecções nosocomiais ou sistêmicas no mundo todo. Devido a sua resistência a várias drogas não $\beta$-lactâmicas, poucas opções terapêuticas podem ser usadas com efetividade, assim, o controle de sua disseminação é crucial, sendo utilizados, para isso, agentes desinfetantes (NORDMANN et al., 2009).

Os extratos de plantas superiores foram e ainda são muito utilizados visando à obtenção de compostos com ação antimicrobiana, contudo, os óleos essenciais têm sido preferidos, uma vez que diminuem parâmetros de isolamento e purificação de compostos, além disso, eles apresentam elevada atividade antimicrobiana e, em concentrações adequadas, são considerados seguros (Generally Recognized as Safe).

Vários estudos mostram a eficácia dos óleos essenciais na inibição do crescimento microbiano (BURT, 2004; TAJKARIMI et al., 2010). Vários de seus compostos possuem atividade antimicrobiana, interferindo na permeabilidade da membrana citoplasmática, causando perdas de constituintes celulares, prejudicando sistemas enzimáticos, inativando ou destruindo o material genético de bactérias (SIKKEMA et al., 1995; BURT, 2004; TAJKARIMI et al., 2010) e causando lise da parede celular (OLIVEIRA et al., 2011).

$\mathrm{Na}$ busca de alternativas para o controle de microrganismos, o sinergismo entre diferentes fatores torna-se interessante (FRANCO \& LANDGRAF, 1996). Sabe-se que os microrganismos, quando expostos a temperaturas subletais, podem sofrer alterações fisiológicas que os tornam mais susceptíveis a outras condições de estresse, quando expostos simultaneamente a essas condições, culminando na morte celular.

Dentre os microrganismos de interesse na área alimentícia e médica, destacam-se Escherichia coli, Staphylococcus aureus e Salmonella Enteritidis, pois estão entre os mais importantes agentes patogênicos causadores de enfermidades em seres humanos, causando gastrenterites e trazendo riscos à saúde pública, além de estarem envolvidos em vários surtos de toxinfecções alimentares em todo mundo (LEUSCHNER \& ZAMPARINI, 2002, GOVARIS et al., 2010; MEIRA et al., 2012).

Assim, neste trabalho, buscou-se determinar a atividade antimicrobiana e a curva de morte termoquímica das bactérias, empregandose soluções desinfetantes dos óleos essenciais de Thymus vulgaris (tomilho), Elettaria cardamomum (cardamomo), Eugenia caryophyllus (cravo da índia), Foeniculum vulgare dulce (funcho doce) sobre Eschericha coli, Salmonella enterica Enteritidis e Staphylococcus aureus.

\section{MATERIAL E MÉTODOS}

Microrganismos utilizados, padronização, estocagem e preparo dos inóculos

Os microrganismos utilizados foram Escherichia coli ATCC 25922, Staphylococcus aureus ATCC 13565, adquiridos da Seção de Coleção de Culturas da Divisão de Biologia Médica do Instituto Adolfo Lutz, São Paulo, SP, Brasil e Salmonella enterica serovar Enteritidis S64, gentilmente cedida pela Fundação Oswaldo Cruz, Rio de Janeiro, RJ, Brasil.

As culturas estoque foram mantidas em meio de congelamento (glicerol; $15 \mathrm{~mL}$; peptona bacteriológica; $0,5 \mathrm{~g}$; extrato de levedura; $0,3 \mathrm{~g} ; \mathrm{NaCl}$; 0,5g; água destilada; $100 \mathrm{~mL} ; \mathrm{pH} 7,2 \pm 7,4) \mathrm{a}-18^{\circ} \mathrm{C}$. As cepas foram reativadas em caldo BHI (Brain Heart Infusion) com incubação a $37^{\circ} \mathrm{C} 24 \mathrm{~h}^{-1}$. Os inóculos foram padronizados em $10^{8} \mathrm{UFC} \mathrm{mL}^{-1}$ após elaboração de curvas de crescimento (D.O. ${ }_{600 \mathrm{~nm}}$ ) em TSB (caldo triptona de soja) e plaqueamento periódico em TSA (ágar triptona de soja) e incubação a $37^{\circ} \mathrm{C} 24 \mathrm{~h}^{-1}$.

\section{Óleos essenciais}

Os óleos essenciais utilizados foram Thymus vulgaris (tomilho), Elettaria cardamomum (cardamomo), Eugenia caryophyllus (cravo da índia, botão) e Foeniculum vulgare dulce (funcho doce) adquiridos da FERQUIMA ${ }^{\circledR}$. 
Concentração Mínima Inibitória (CMI)

Foi utilizada a técnica de diluição em ágar (NCCLS, 2003) com modificações. Os óleos essenciais foram homogeneizados em TSA, contendo $0,5 \%$ de Tween 80, obtendo-se as concentrações em (v/v) de: 0,$00 ; 0,25 ; 0,5 ; 1,0 ; 2,0 ; 2,5 ; 3,0 ; 3,5 ; 4,0 ; 4,5 ;$ e $5,0 \%$ e distribuídas em placas de Petri. Alíquotas de $0,1 \mathrm{~mL}$ das culturas padronizadas das bactérias foram transferidas para as placas e incubadas a $37^{\circ} \mathrm{C} 24 \mathrm{~h}^{-1}$. As menores concentrações dos óleos essenciais que resultaram em completa inibição do crescimento bacteriano no meio de cultura foram denominadas de CMI.

\section{Curvas de morte termoquímica}

A influência dos óleos essenciais e da temperatura sobre o tempo de inativação de S. aureus, E. coli e $\boldsymbol{S}$. Enteritidis foi avaliada empregando-se o teste de diluição (ANDRADE \& MACEDO, 1996). As soluções desinfetantes foram preparadas com a CMI dos óleos essenciais (foram selecionados aqueles com valores de CMI menores que $1 \%$ ) homogeneizados em água peptonada $0,1 \%$ $(\mathrm{m} / \mathrm{v})$, contendo $10 \%$ de etanol. Alíquotas de $1 \mathrm{~mL}$ das suspensões bacterianas padronizadas foram transferidas para tubos contendo $9 \mathrm{~mL}$ das diferentes soluções. Após 10s, 10, 20 e 30min de exposição a 25 e $40^{\circ} \mathrm{C}$, alíquotas de $1 \mathrm{~mL}$ das suspensões foram transferidas para tubos contendo água peptonada $0,1 \%(\mathrm{~m} / \mathrm{v})$, sendo realizadas diluições seriadas. A enumeração das células viáveis foi realizada por plaqueamento em superfície em TSA e incubação a $37^{\circ} \mathrm{C} 24 \mathrm{~h}^{-1}$.

Delineamento experimental e análise estatística

O delineamento experimental utilizado foi o inteiramente casualizado (DIC) com três repetições em esquema fatorial. Os dados foram submetidos à análise de variância e as médias comparadas pelo teste Scott Knott a 5\% de probabilidade e, ou, análise de regressão.

As análises estatísticas foram realizadas empregando-se o software Sisvar versão 4.6.

\section{RESULTADO E DISCUSSÃO}

Escherichia coli, S. aureus e $S$. Enteritidis apresentaram diferentes sensibilidades aos óleos essenciais testados. O óleo essencial com maior atividade antimicrobiana sobre todas as bactérias foi o de tomilho, com CMI de 0,25\%. O de cravo da índia foi efetivo apenas sobre $\boldsymbol{E}$. coli com MIC de $0,25 \%$. Já os de funcho doce e cardamomo não apresentaram atividade antimicrobiana como o óleo de tomilho, inibindo S. aureus nas CMI de $4 \%$ e $1 \%$, respectivamente e $\boldsymbol{E}$. coli na CMI de $1 \%$. S. Enteritidis não foi sensível a esses óleos.

Visando a diminuir o forte odor dos óleos essenciais, característica indesejável em produto desinfetante, tanto na área médica quanto na indústria de alimentos, somente aqueles cuja CMI foi menor ou igual a $1 \%$ foram selecionados para o desenvolvimento deste trabalho. As curvas de morte termoquímica das bactérias expostas aos óleos essenciais são apresentadas nas figuras 1e 2 .

Avaliando-se a sensibilidade de $S$. aureus às soluções sanificantes dos óleos essenciais de cardamomo e tomilho, associada à temperatura e ao tempo de desinfecção, não foi observada influência significativa da temperatura, contudo, houve interação significativa entre os tratamentos com os óleos essenciais e o tempo de desinfecção (Figura 1A). Após $30 \mathrm{~min}$. de desinfecção com óleo essencial de cardamomo, houve redução significativa $(4,29 \mathrm{Log}$ UFC $\mathrm{mL}^{-1}$ ) do número de células de $\boldsymbol{S}$. aureus, já para a solução contendo óleo de tomilho, células viáveis não foram mais detectadas após $10 \mathrm{~min}$. (redução de 6,97Log UFC $\mathrm{mL}^{-1}$ ). Pode-se observar na figura 1 que o rápido contato (10s) das células, tanto de $S$. aureus quanto $\boldsymbol{S}$. Enteritidis, com as soluções sanificantes foi suficiente para promover redução do número de células viáveis quando comparado ao controle, cujo tempo de exposição não influenciou na morte das células.

Salmonella Enteritidis foi submetida ao processo de desinfecção utilizando-se apenas o óleo essencial de tomilho (Figura 1B). Houve interação significativa entre tratamento, tempo e temperatura de exposição das células. A temperatura da solução controle não influenciou na viabilidade celular de $S$. Enteritidis e o rápido contato do inóculo com a solução desinfetante (10s), tanto a $25^{\circ} \mathrm{C}$ quanto a $40^{\circ} \mathrm{C}$, reduziu o número de células viáveis, respectivamente, em 2,62 e 5,14Log $\mathrm{UFC} \mathrm{mL}^{-1}$. Após 10 min. não foram detectadas células viáveis de $S$. Enteritidis (redução de 7,4 Log UFC $\mathrm{mL}^{-1}$ ).

Escherichia coli se mostrou a bactéria mais sensível aos óleos essenciais testados. Houve interação significativa entre os tratamentos, temperatura e tempo de desinfecção, não sendo observada influência da temperatura na viabilidade celular das células da solução controle. A figura 2 mostra as curvas de morte termoquímica de $\boldsymbol{E}$. coli exposta às soluções desinfetantes de óleos essenciais de cardamomo, $1 \%$, cravo da índia, 0,25\%, funcho doce $1 \%$ e tomilho, $0,25 \%$. $\boldsymbol{E}$. coli foi mais sensível às soluções sanificantes contendo óleo essencial de funcho doce e cravo da índia (redução de 6,5Log 


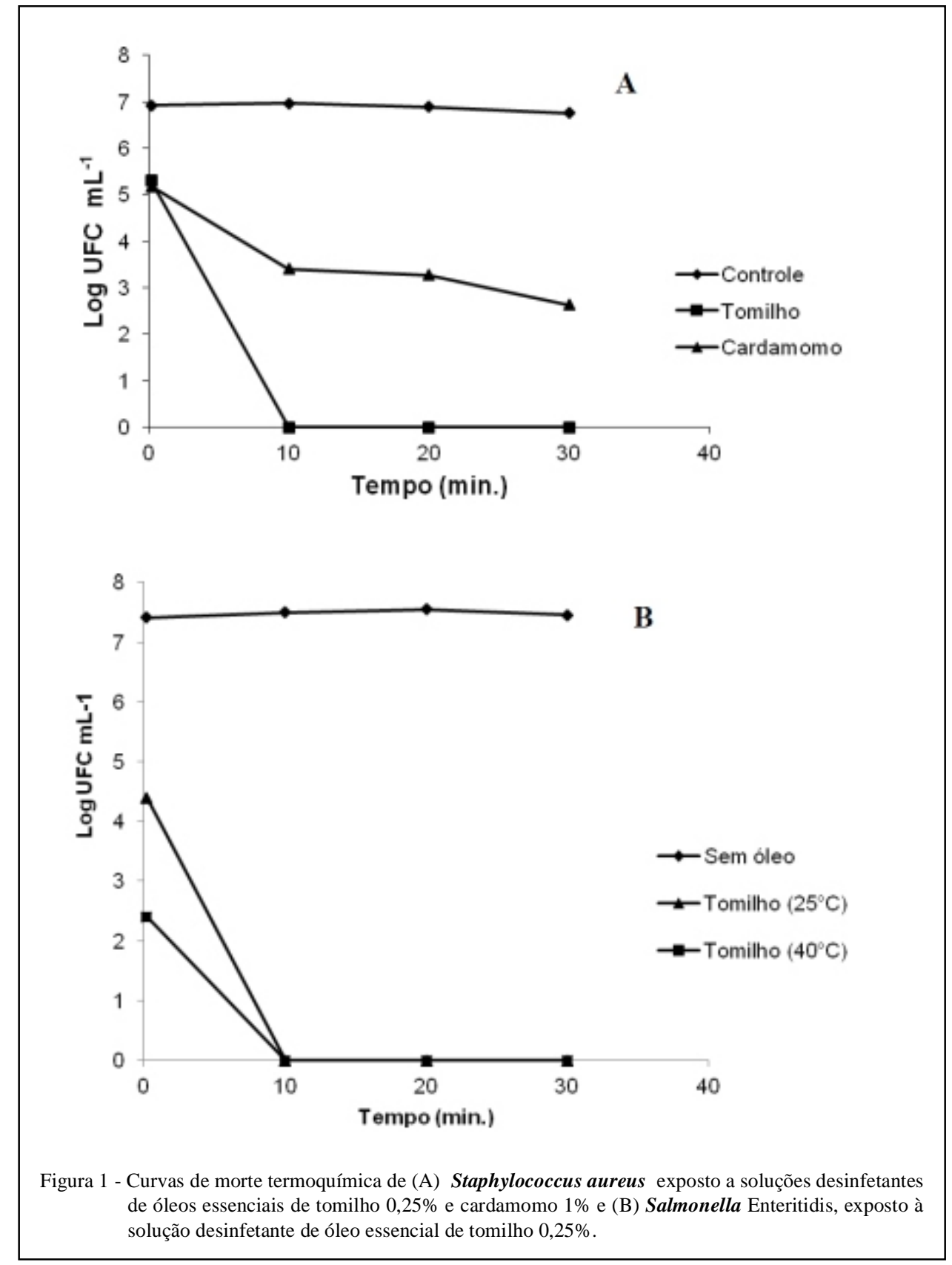

UFC $\mathrm{mL}^{-1}$ ) a $40^{\circ} \mathrm{C}$, após $10 \mathrm{~s}$ de contato, do que a $25^{\circ} \mathrm{C}$, cujo ciclo Log foi o mesmo, porém após $10 \mathrm{~min}$ de contato (Figura 2A).

A solução sanificante contendo óleo essencial de tomilho não foi eficiente sobre $\boldsymbol{E}$. coli em ambas as temperaturas, como o observado para $S$. aureus e $\boldsymbol{S}$. Enteritidis. A $25^{\circ} \mathrm{C}$, houve redução de 4,51Log UFC $\mathrm{mL}^{-1}$ após 30min. de desinfecção. Já a $40^{\circ} \mathrm{C}$, não foram detectadas células viáveis após 10min de contato (redução de $6,5 \mathrm{Log} \mathrm{UFC} \mathrm{mL}^{-1}$ ). A solução contendo óleo de cardamomo foi aquela com menor atuação sobre $\boldsymbol{E}$. coli. Embora a temperatura tenha influenciado significativamente na morte celular, 30min de tratamento não foram suficientes para eliminar as células bacterianas.

$\mathrm{Na}$ literatura, sugere-se que a atividade antimicrobiana dos óleos essenciais está relacionada principalmente ao seu composto majoritário, embora 


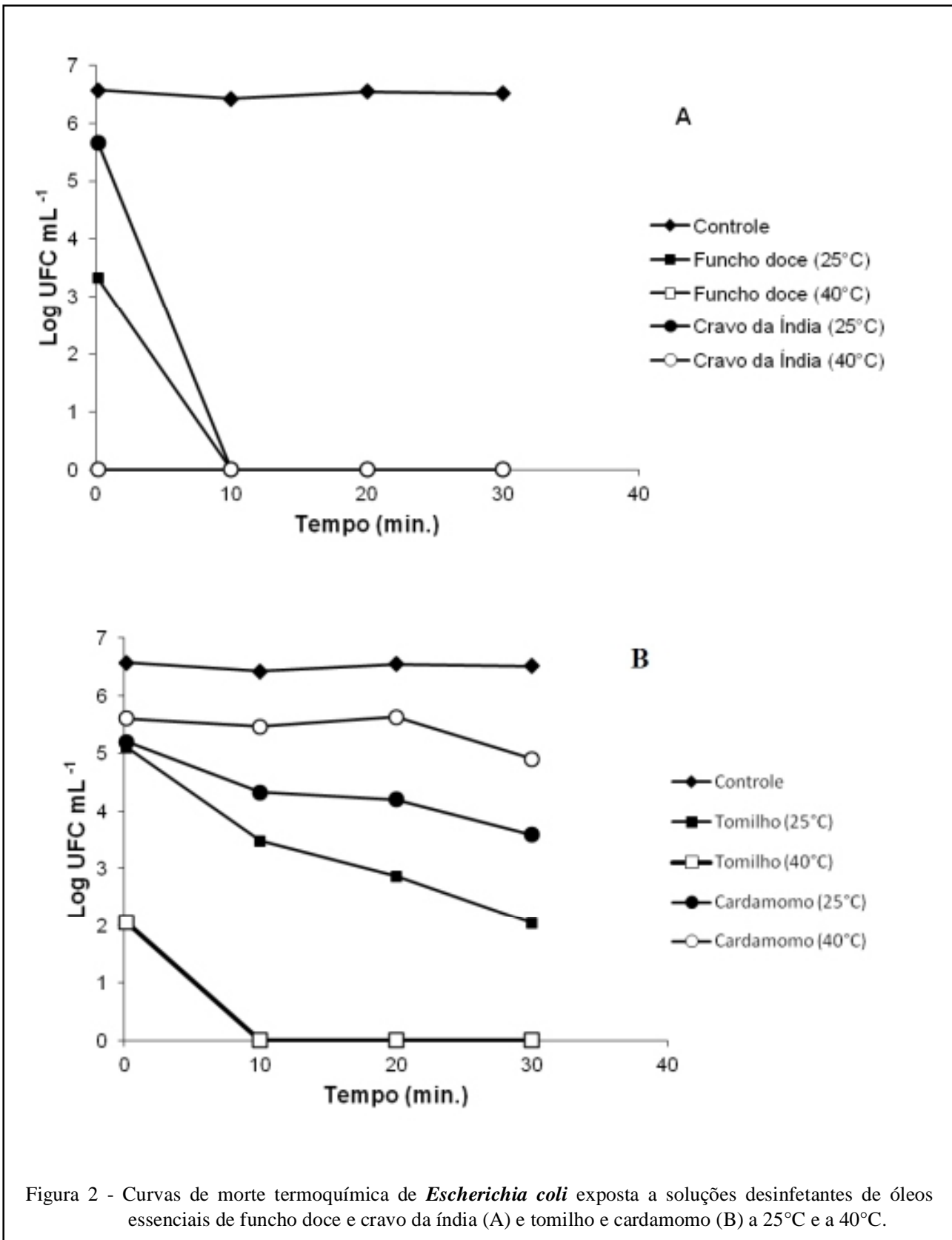

alguns autores mencionem a sinergia com os compostos minoritários (BURT, 2004; BAKKALI et al., 2008). A solução desinfetante contendo $0,25 \%$ de óleo essencial de cravo da índia matou as células de E.coli. Esse óleo contém os compostos majoritários eugenol 85,3\%; $\beta$-cariofileno $11,8 \%$ e $\alpha$-humuleno, 1,5\%; segundo cromatograma disponibilizado no sítio da empresa FERQUIMA para o lote utilizado nessa pesquisa. Apesar de não ser o único componente que desempenhe ação antibacteriana, o eugenol tem sua atividade antimicrobiana comprovada (LEUSCHNER \& ZAMPARINI, 2002; QIU et al., 2010).

MOREIRA et al. (2005), estudando vários óleos essenciais contra $\boldsymbol{E}$. coli O 157:H7, observaram maior efetividade do óleo de cravo da índia, MIC de $0,25 \%$, igual ao valor encontrado para o presente trabalho. Contudo, a ação bactericida do óleo essencial em BHI não foi satisfatória (3,5 ciclos Log) após $15 \mathrm{~min}$ 
de contato a $20^{\circ} \mathrm{C}$, não sendo observada alteração desse resultado mesmo após $20 \mathrm{~h}$. No presente trabalho, com a temperatura de exposição de $25^{\circ} \mathrm{C}$ ou $40^{\circ} \mathrm{C}$, a redução do ciclo Log foi de 6,5 após 10min de contato.

Diferenças na atividade antibacteriana existentes entre óleos essenciais de diferentes espécies de plantas, como as observadas entre os óleos estudados, são atribuídas aos seus compostos químicos (TAJKARIMI et al., 2010). A eficácia do óleo depende do $\mathrm{pH}$ da solução, temperatura de tratamento e das concentrações e tipo de componentes ativos (BURT, 2004).

Os compostos majoritários do óleo essencial de tomilho utilizado foram o timol, 47,3\%, e o p-cinemo, 26,8\%, segundo cromatograma disponibilizado no sitio da FERQUIMA, para o lote de óleo adquirido. O timol é um composto fenólico, com ação antimicrobiana efetiva. A eficiência da solução sanificante a base de óleo essencial de tomilho a $0,25 \%$ sobre $\boldsymbol{S}$. aureus, $\boldsymbol{E}$. coli e $\boldsymbol{S}$. Enteritidis pode ser atribuída à ação desses compostos, que ocorre sobre a membrana celular, onde o timol desorganiza a estrutura celular, promovendo desnaturação de enzimas essenciais (BURT, 2004). Além do timol, o óleo também continha carvacrol $(3,1 \%)$ que juntamente com o p-cimeno $(26,8 \%)$ possuem atividade antibacteriana e antifúngica.

A alta atividade bactericida da solução sanificante do óleo essencial de Funcho doce sobre E. coli e baixa atividade sobre $\boldsymbol{S}$. aureus difere de estudos que relatam que bactérias Gram positivas são mais sensíveis a óleos essenciais do que as Gram negativas, devido ao lipopolissacarídeo presente na membrana externa (OUSSALAH et al., 2007). Porém, BURT (2004) afirma que bactérias Gram positivas têm sido menos ou igualmente sensíveis a bactérias Gram negativas.

O óleo essencial de cardamomo possui como principais componentes o alfa-terpineol (3\%), acetato de terpenila (36\%), linalol $(5 \%)$ e cineol na concentração de $34 \%$, e sua solução sanificante a $1 \%$, apesar de inibir o crescimento de $\boldsymbol{E}$. coli e $\boldsymbol{S}$. aureus não mostrou atividade bactericida nos tempos e temperaturas estudados, embora MALTI et al. (2007) tenham observado atividade antimicrobiana sobre bactérias Gram positivas e negativas e encontraram resultados satisfatórios ao avaliar o óleo essencial dessa especiaria.

A solução sanificante a base de óleo essencial de tomilho foi a que mostrou os melhores resultados, apresentando atividade bactericida sobre E. coli, $S$. aureus e $\boldsymbol{S}$. Enteritidis, proporcionando ciclos Log maiores que 5 , valor sugerido para que o sanificante seja considerado eficiente (ANDRADE
\& MACEDO, 1996). As soluções a base de óleo de funcho doce e cravo apresentaram melhores resultados sobre $\boldsymbol{E}$. coli e $\boldsymbol{S}$. aureus, enquanto que a solução sanificante de cardamomo não mostrou atividade bactericida satisfatória sobre nenhum dos microrganismos estudados.

\section{CONCLUSÃO}

A solução desinfetante de tomilho $0,25 \%$ foi a mais eficiente dentre todas as soluções testadas. A solução desinfetante de cardamomo $1 \%$ não reduziu o número mínimo de células viáveis das bactérias testadas, não sendo considerada efetiva.

\section{AGRADECIMENTOS}

Os autores agradecem à Fundação de Amparo à Ciência do Estado de Minas Gerais (FAPEMIG) pelo apoio financeiro (CBB - APQ-01758-11) e bolsa de iniciação científica concedidos e ao Conselho Nacional de Desenvolvimento Científico e Tecnológico ( $\mathrm{CNPq}$ ) pelas bolsas de doutorado e iniciação científica concedidas.

\section{REFERÊNCIAS}

ANDRADE, N.J.; MACEDO, J.A.B. Higienização na indústria de alimentos. São Paulo: Varela, 1996. 165p.

BAKKALI, F. et al. Biological effects of essential oils - a review. Food and Chemical Toxicology, v.46, n.2, p.446-475, 2008. Disponível em: <http://dx.doi.org/10.1016/j.fct.2007.09.106>. Acesso em: 15 dez. 2013. doi: 10.1016/j.fct.2007.09.106.

BURT, S. Essential oils: their antibacterial properties and potential applications in foods-a review. International Journal of Food Microbiology, v.94, n.3, p.223-253, 2004. Disponível em: <http:// dx.doi.org/10.1016/j.ijfoodmicro.2004.03.022>. Acesso em: 14 dez. 2013. doi: 10.1016/j.ijfoodmicro.2004.03.022.

FRANCO, B.D.G.M.; LANDGRAF,M. Microbiologia de alimentos. Rio de Janeiro: Atheneu, 1996. 182p.

DAVIDSON, P.M.; HARRISON, M.A. Resistance and adaptation to food antimicrobials, sanitizers, and other process controls. Food Technology-Champaign then Chicago, v.56, n.11, p.69-78, 2002.

GOVARIS, A. et al. The antimicrobial effect of oregano essential oil, nisin and their combination against Salmonella enteritidis in minced sheep meat during refrigerated storage. International of Food Microbiology, v.137, p.175-180, 2010. Disponível em: <http://dx.doi.org/10.1016/j.ijfoodmicro.2009.12.017>. Acesso em: 20 dez. 2013. doi: 10.1016/j.ijfoodmicro.2009.12.017.

LEUSCHNER, R.G.K.; ZAMPARINE, J. Effect of spices on growth and survival of Escherichia coli O 157 and Salmonella enterica serovar Enteritidis in broth model systems and mayonnaise. Food Control, v.13, p.399-404, 2002.

MALTI, J.E. et al. Antimicrobial activity of Elletaria cardamomum: Toxicity, biochemical and histological studies. 
Food Chemistry, v.104, p.1560-1568, 2007. Disponível em: <http://dx.doi.org/10.1016/j.foodchem.2007.02.043>. Acesso em: 21 dez. 2013. doi: 10.1016/j.foodchem.2007.02.043.

MEIRA, Q.G.S. et al. Influence of temperature and surface kind on biofilm formation of Staphylococcus aureus from foodcontact surface and sensitivity to sanitizers. Food Control, v.25, p.469-475, 2012. Disponível em: <http://dx.doi.org/10.1016/j. foodcont.2011.11.030>. Acesso em: $21 \mathrm{dez} .2013$. doi:10.1016/j. foodcont.2011.11.030.

MOREIRA, M.R. et al. Inhibitory parameters of essential oils to reduce a foodborne pathogen. LWT - Food Science and Technology, v.38, p.538-570, 2005. Disponível em: <http:// dx.doi.org/10.1016/j.lwt.2004.07.012>. Acesso em: 20 dez. 2013. doi:10.1016/j.lwt.2004.07.012.

NCCLS (NATIONAL COMMITTEE FOR CLINICAL LABORATORY STANDARDS). Methods for dilution antimicrobial susceptibility tests for bacteria that grow aerobically. Wayne, Pa: USA, 2003. (Approved standard M7-A6).

NORDMANN, P. et al. The real threat of Klebsiella pneumonia carbapenemase-producing bacteria. Lancet infectious diseases, v.9, n.4, p.228-236, 2009. Disponível em: <http://dx.doi. org/10.1016/S0140-6736(08)61345-8>. Acesso em: 20 dez. 2013. doi: 10.1016/S0140-6736(08)61345-8.
OLIVEIRA, T.L.C. et al. Antimicrobial activity of Satureja montana L. essential oil against Clostridium perfringens type A inoculated in mortadella- type sausages formulated with different levels of sodium nitrite. International Journal of Food Microbiology, v.144, n.3, p.546-555, 2011. Disponível em: <http://dx.doi.org/10.1016/j.ijfoodmicro.2010.11.022〉. Acesso em: 21 dez. 2013. doi:10.1016/j.ijfoodmicro.2010.11.022.

OUSSALAH, M. et al. Inhibitory effect of selected plant essential oils on the growth of four pathogenic bacteria: E. coli O157:H7, Salmonella Typhimurium, Staphylococcus aureus and Listeria monocytogenes. Food Control, v.18, p.414-420, 2007. Disponível em: <http://dx.doi.org/10.1016/j.foodcont.2005.11.009>. Acesso em: 10 dez. 2013. doi: 10.1016/j.foodcont.2005.11.009.

QIU, J. et al. Eugenol reduces the expression of virulencerelated exoproteins in Staphylococcus aureus. Applied and Environmental Microbiology, v.76, n.17, p.5846-5851, 2010. Disponível em: <http://dx.doi.org/10.1128/AEM.00704-10〉. Acesso em: 20 dez. 2013. doi: 10.1128/AEM.00704-10.

SIKKEMA, J. et al. Mechanisms of membrane toxicity of hydrocarbons. Microbiological Reviews, v.59, n.2, p.201-222, 1995.

TAJKARIMI, M.M. et al. Antimicrobial herb and spice compounds in food. Food Control, v.21, n.9, p.1199-1218, 2010. Disponível em: <http://dx.doi.org/10.1016/j.foodcont.2010.02.003>. Acesso em: 22 dez. 2013. doi: 10.1016/j.foodcont.2010.02.003. 